\title{
DENTAL IMPLANT TISSUE INTERFACE - AN APPRAISAL
}

Taiyeb Ali TB. Dental implant tissue interface - an apprsisal, Annals Dent Univ Malaya 1997; 4: 39-43

\begin{abstract}
Endoseous Implant insertion for the replacement of missing teeth is the state of the art at present times. An understanding of the biology of the perimplant tissues is imperative for the overall success in the dental rehabilitation of a patient with fixture supported prosthesis. The dental implant tissue interface comprises bone, both cortical and cancellous bone; supracrestal connective tissue and the epithelial attachment. A comprehensive review of the response of bone during the postoperative or healing phase, the loading or remodelling phase and during the steady phase is described.
\end{abstract}

Key words: dental implant, tissue- implant interface.

\section{INTRODUCTION}

Implant placement for the replacement of missing teeth is the state of the art at present times. With advent in implant technology and increase in implant placement, knowledge and understanding of biology is essential to ensure osseointegration of implants. An understanding of the biology of perimplant tissues is imperative for overall success in dental rehabilitation of a potential patient for fixture supported prosthesis. The accepted criteria for successful osseointegration of implants $(1,2)$ are as follows:

1) dental implants should not be mobile and no periimplant radiolucencies should be evident in radiographs

2) alveolar bone loss should not exceed $0.2 \mathrm{~mm}$ annually after the first year and there should be no infection, paraesthesia or other implant related neuropathy.

The present clinical approach in dental implantology is focused on endosseous implants. These implants are artificial inorganic tooth substitutes exogenously introduced into an endogenous receptor site with the expectation that the surrounding tissue will adapt to them physiologically allowing function during mastication. This adaptation of the surrounding tissue to the implants results in an implant-tissue (IT) interface (Fig 1) which comprises:

1) Bone

2) Supracrestal/subepithelial connective tissue.

3) Epthelial attachment with or without gingival sulcus and a junctional epithelium.

The development and maintenance of viable I-T interface is of paramount importance in the determination of clinical success in implant dentistry. Early studies on this interface were mainly by Albrektsson(3,4), Schroeder(5) and Listgarten(6). It is to be noted that cementum progenitor cells are missing in this interface, hence precluding the development of a functional periodontal ligament (PL). As a consequence, implants do not have the same mobility as natural teeth which have the periodontal ligament(PL) that act as a "shock absorbing element" on application of a load. The absence of the PL precludes the ability of the implant fixtures to absorb any excessive loading. However recent studies have shown
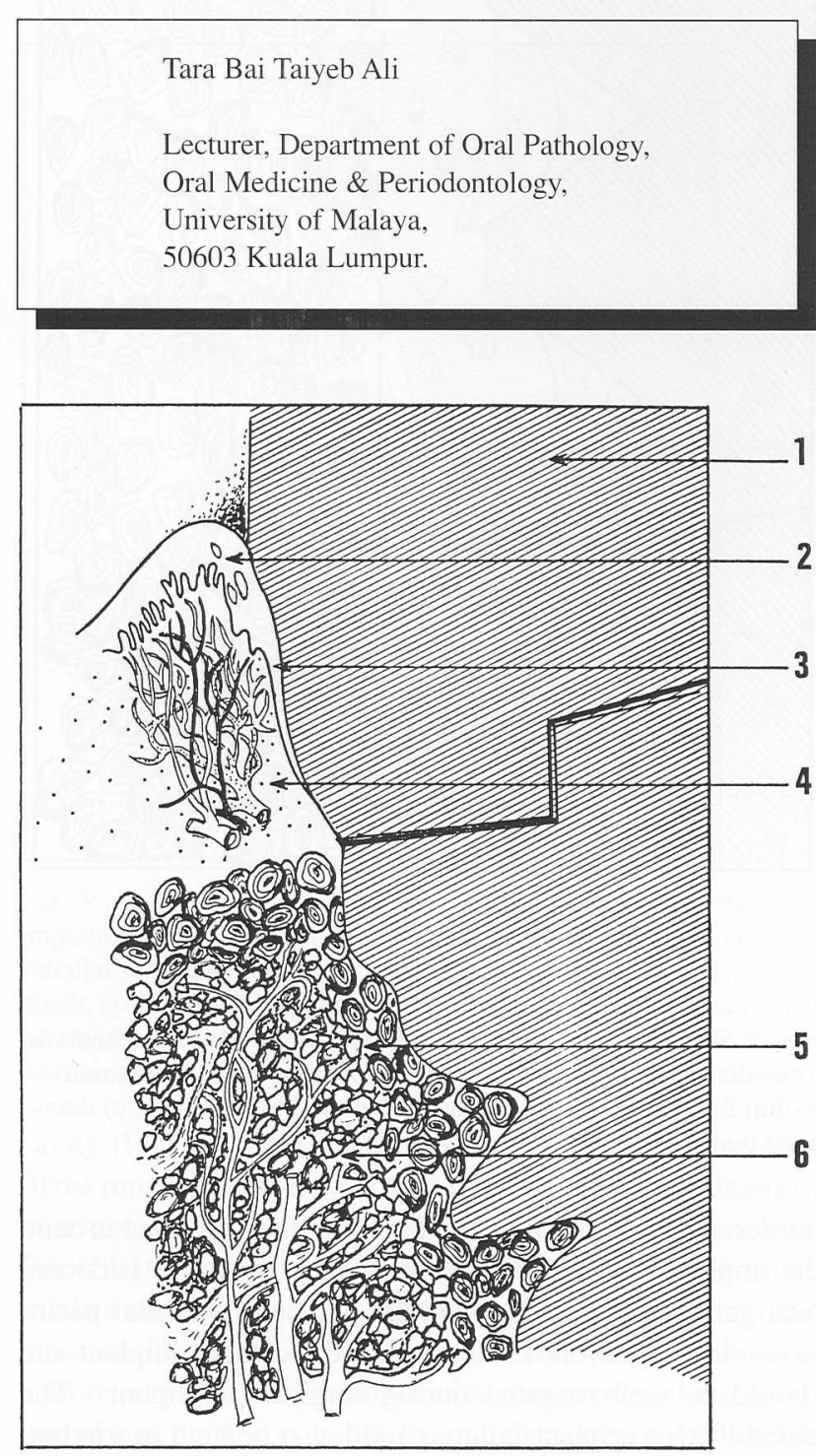

Fig. 1: Diagrammatic representation of the dental implant - tissue interface. 1) implant fixture, 2) epithelium, 3) junctional epithelium, 4) subepithelial / supracrestal connective tissue, 5) cortical bone, 6) cancellous bone.

formation of PL around the surface of implants when progenitor cells from PL of a residual root tip was left in close contact with an implant surface (7). The ultimate goal in implant research is to establish a biologically comparable I$\mathrm{T}$ interface so that load distribution on an implant will be closer to physiological stresses on the surrounding bone.

\section{Postoperative Bone Tissue Response}

Bone is highly cellular and vascular. A predictable outcome of bone implant complex is achieved when the fixture site in bone is congruent with implant fixture anatomy. During surgical implant placement, a wound is created and thus understanding of wound healing and cellular response is essential for predictable results.

On insertion of an implant into the jaw bone, a necrotic 


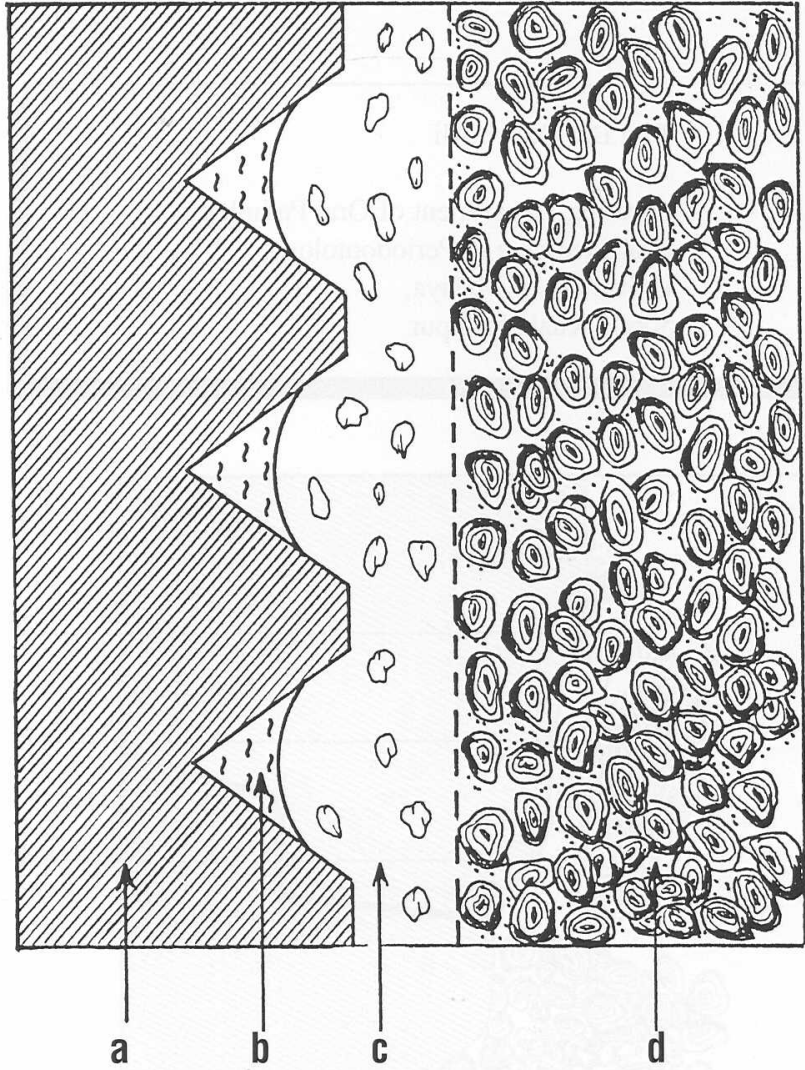

Fig. 2: Schematic representation of the biology of the implant site immediately postoperatively. a) implant fixture, b) haematoma within the threads of the implant fixture in closed cavity, c) damaged bone, c) original undamaged bone.

border zone results (Fig 2). The width of this zone around the implant depends on two main factors i.e. the frictional heat generated at surgery and the degree of vascular perfusion. It is therefore essential that the created implant site should be well irrigated during surgical placement. The possibility of implant failure would also be high in irradiated bone where vascular perfusion is compromised.

Bone tissue may react to necrosis in the border zone in 2 different ways $(8,9)$ :

1) with fibrous tissue formation when severe trauma in physical, thermal, chemical or other forms is inflicted. This remains as a sheath of non-mineralised connective tissue (Fig 3).

2) healing with complete replacement with new bone resulting in osseointegration (Fig 4).

Bone condensation occurs around an implant device when adequate bone response prevails. The repair of the necrotic border zone depends on the coupled osteoclastosteoblast creeping action known as creeping substitution. Hence stages in the bone growth include:

1) Dense vascular ingrowth

2) Woven bone or callus formation with the osteogenic front moving 25-50 mm per day.

3) Replacement by mature lamellar bone.

Remodelling of the anchoring bone follows with gradual functional adaptation. The modelling and remodelling of perimplant bone may be categorised into 3 partly overlapping

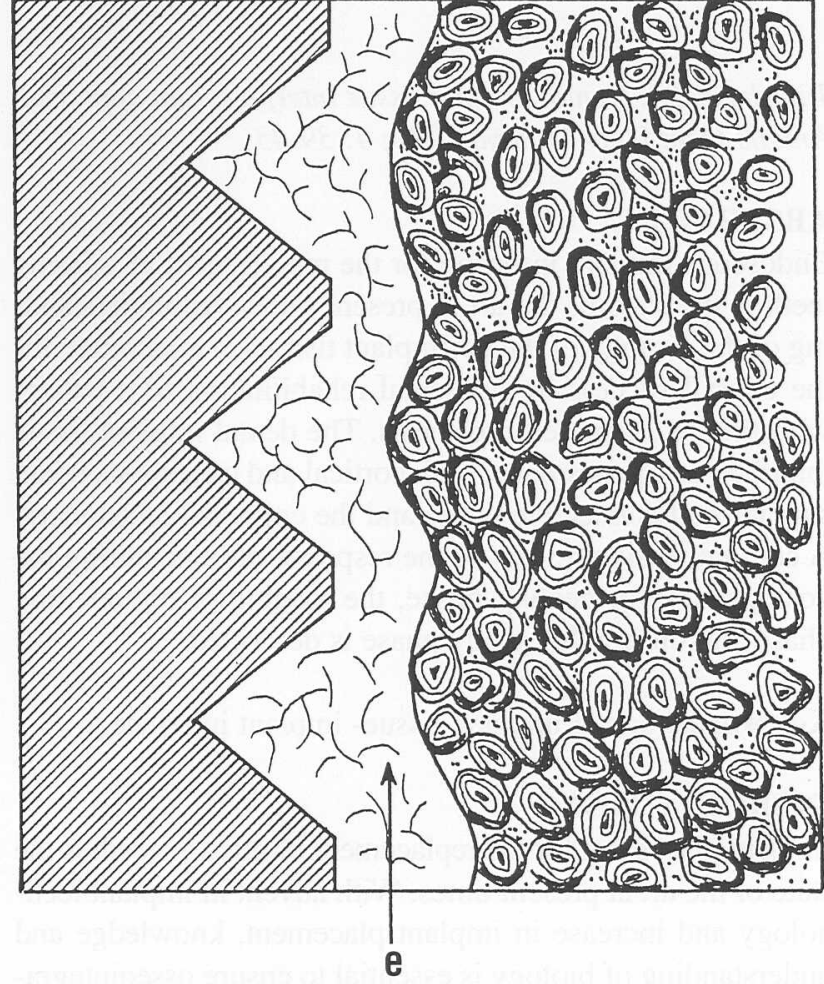

Fig. 3: Schematic representation of the biology of the implant in unsuccessful cases, with non-osseointegration. e) non-mineralised connective tissue in the border zone as a result of surgical trauma, infection, early loading or excessive loading.

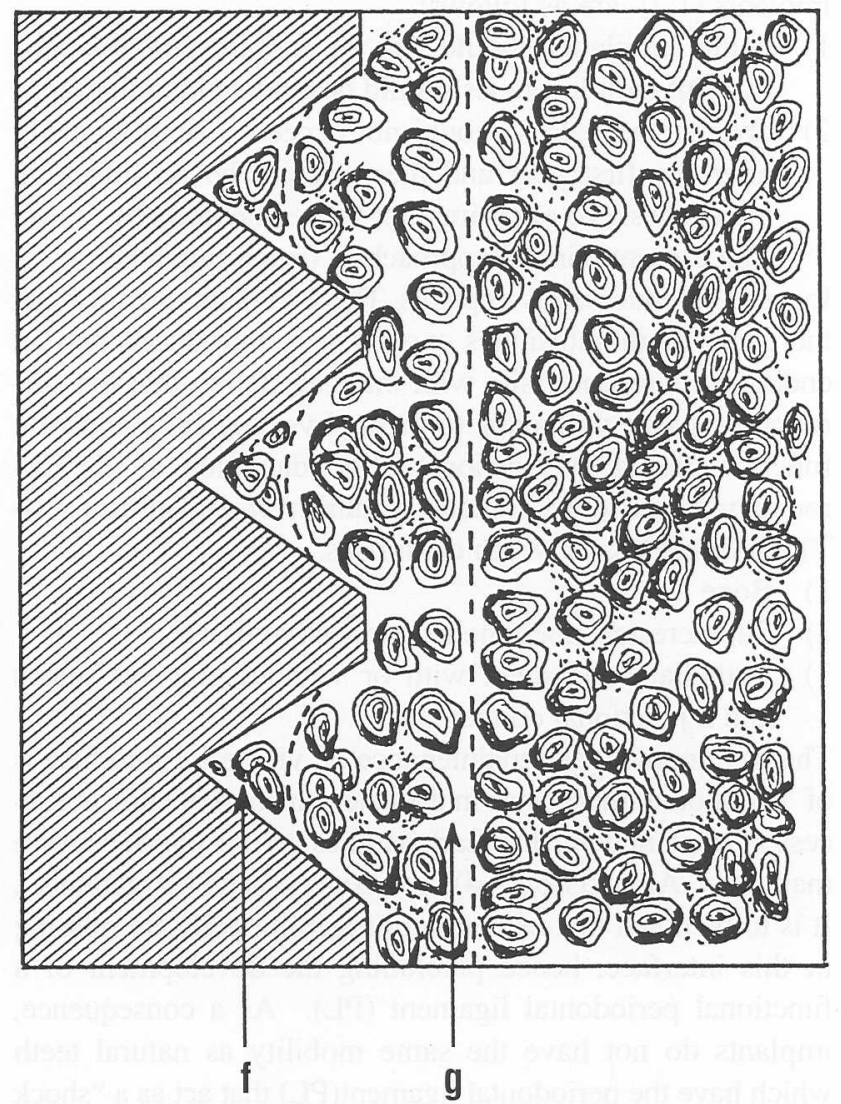

Fig. 4: Schematic representation of the biology of the healed site of an osseointegrated unloaded dental implant. f) new bone replacing the haematoma, g) new bone replacing the damaged bone 
stages (10). First, the healing phase, during which new bone forms close to the immobile resting implant. This phase lasts about 3 months and osteointegration is established. When the implant is exposed to masticatory forces, the remodelling phase which occurs over a 12 to 18 months period takes place. Newly formed bone remodels according to the magnitude, direction and frequency of the applied load. Finally the steady phase is established after about 18 months when balance is achieved between the forces acting on the implant and the remodelling capacities of the anchoring bone. Although healing as described above occurs in the majority of cases, potential factors exist which may contribute to failure in osseointegration as follows:

1. Traumatising surgery during implant placement may result in frictional heat and this heat will contribute to the necrosis of cells thereby resulting in soft tissue anchorage (11).

2. Preoperative irradiation may impair healing (10). However the negative influence decreases with time $(12,13)$.

3. Medical health status e.g. Rheumatoid arthritis which produces a low healing potential.

4. Implant movements particularly in premature loading causing the development of a fibrous tissue interface (8).

\section{Bone Implant Interface}

Optimal healing after implant placement reveals intimate contact with bone at the implant interface. All features of ankylosis known as osseointegration are noted. This interface has been investigated using histological sections, scanning election microscopy (SEM) and transmission election microscopy (TEM).

The undecalcified ground sections show the surface coverage around titanium implants by cortical bone consist upto 90\% mineralised lamellar bone. Where cancellous bone is found, such contact is for about $50 \%$ of the implant surface with the remaining surface being in direct contact with nonmineralised bone marrow, consisting of unmineralised collagen fibres, connective tissue cells and proteinaceous matrix. A very narrow interface layer of 1-10 microns of proteoglycans and glycosaminoglycans is present over the titanium implant surface (14). In the modelling and remodelling of perimplant bone after occlusal loading the ankylotic contact is more intimate and the bone is denser.

Under scanning electron microscope (SEM) and transmission electron microscope (TEM), osteoblasts are found directly on the implant interface and osteocytes in lacunae close to the implant surface $(15,16)$ indicating the biocompatibility of titanium. A 200-400A thick proteoglycan coat is also found adjacent to the surface in titanium implants (17).

\section{Supracrestal Connective Tissue}

All dental implants will penetrate through the supracrestral region where close contact of the gingival epithelium or alveolar mucosa with the implant is expected. Histologically the mucoperiosteum surrounding the transmucosal region of the abutment show soft tissue cells, collagen and ground substance which appear to create a tight seal towards the oral

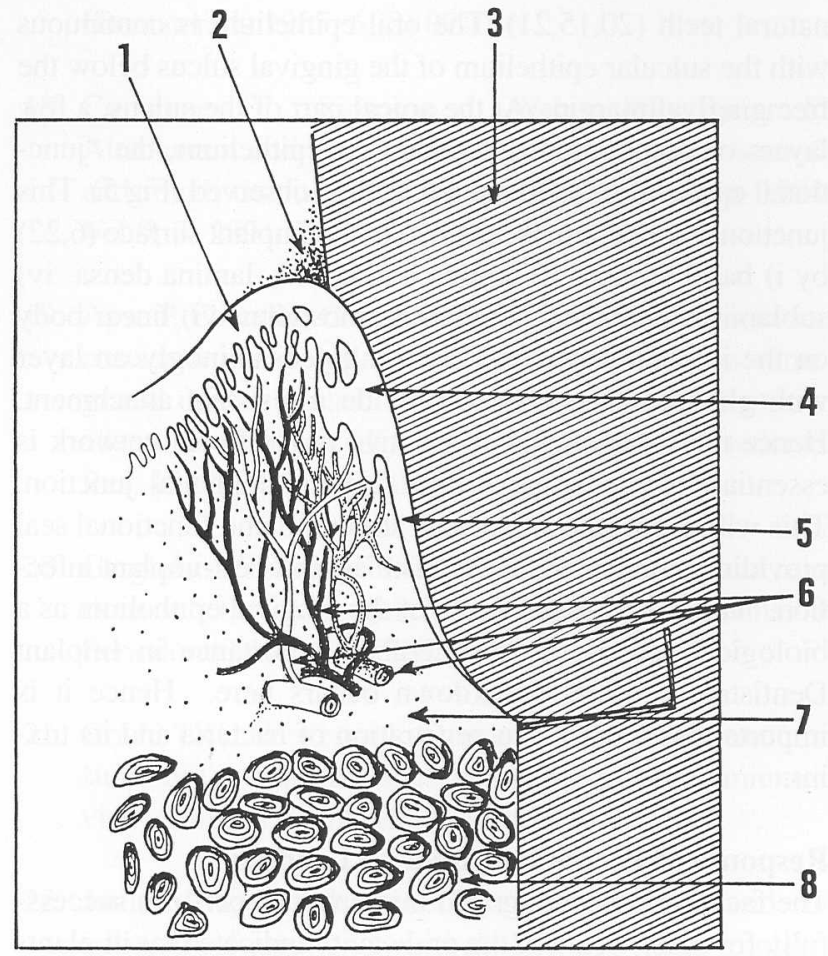

Fig. 5: Diagramatic representation of the soft tissues in the periimplant region. 1) oral epithelium, 2) plaque, 3) implant fixture, 4) sulcular epithelium, 5) junctional epithelium, 6) vascular \& lymphatic system, 7) supracrestal / subepithelial connective tissue comprising the connective tissue cells, fibres \& ground substance, 8) cortical alveolar bone.

cavity (Fig 5). There exist a distinct region of supracrestal fibres running parallel with the long axis of implant abutment in an apico-coronal direction (6) in smooth implant surfaces. Fibroblasts were observed to orientate at acute angle to the implant surface. In rough surface implants e.g. titanium plasma coated implants, the supracrestal fibres were orientated in a more perpendicular arrangement, almost mimicking insertion of functionally oriented dentogingival fibres. Fibroblasts here were found to be at right angles to the fixture surface. (18). This is close to the concept of biologic width seen in natural teeth.

Where the implant penetrates through nonkeratinised alveolar mucosa, parallel fibre orientation is seen. Significance of this for the longevity of the implant is not fully elucidated. However it has been noted that quality of tissue at the perimucosal region has little effect on the clinical indices. Lack of keratinized gingiva around implants did not result in higher gingival and bleeding indices or increased pocket depths (19). Parallel running supracrestal connective tissue fibres splice with circumferentially oriented fibres resulting in the formation of a mechanical cuff which provides an effective structural and functional seal. Coronal to the supracrestal fibres, in the area adjacent to the junctional epithelium, some inflammatory cell infiltrate is found. Apical to this junctional epithelium the tissues are free from inflammatory infiltrate in a healthy situation.

\section{Epithelial Attachment}

The epithelial contact around implants is similar to that with 
natural teeth $(20,15,21)$. The oral epithelium is continuous with the sulcular epithelium of the gingival sulcus below the free gingival margin. At the apical part of the sulcus, a few layers of non-keratinized squamous epithelium, the "junctional epithelium" as in natural teeth is observed (Fig 5). This junctional epithelium is attached to the implant surface $(6,22)$ by i) basal lamina ii) lamina lucida iii) lamina densa iv) sublamina lucida and v) hemidesmosomes vi) linear body on the implant surface. This is a glycosaminoglycan layer with gluelike properties to provide a resistant attachment. Hence the subepithelial connective tissue fibres network is essential for mediating a tight implant-epithelial junction. This will contribute an optimal structural and functional seal providing a protective mechanism against peri-implant infection. The concept of the role of the gingival epithelium as a biological seal is of considerable importance in Implant Dentistry as initial breakdown occurs here. Hence it is important as a barrier to penetration of bacteria and its toxins.

\section{Response of Perimplant Bone to Loading}

The fact that osseointegrated implants can perform successfully for many years in the oral cavity indicate that implants can transfer loads from fixture to bone without progressive failure or loosening $(7,9)$. However there is still a great deal of research being done to assess the distribution of these stresses and the response of bone to these stresses in the different designs of implant systems.

The total fixture surface stress distribution depends on:

i) configuration and surface characteristics of the implant

ii) functional and parafunctional loads on the implant comparable to the natural dentition.

iii) accuracy of fit of the prosthesis.

iv) cantilever extension of the bridge $(24,25)$.

Impeccable prosthodontics is desired to optimise stress distribution via prosthesis to the supporting bone. With attachment of the prosthetic device, perifixtural bone experiences effects from loading of the implant (26). There is usually 1 to $1.5 \mathrm{~mm}$ of marginal alveolar bone loss during the first year after prosthetic rehabilitation possibly as a response to the surgical trauma (24) and subsequent remodelling loss of 0.05 to $0.1 \mathrm{~mm}$ per year (27).

Load transferred to bone may initiate bone resorption (28). When threaded implants are used, stress is concentrated around thread tips. Bone in this area undergoes resorption and is replaced with highly cellular fibrous stroma. Ossification then occurs in the fibrocellular tissue within 5 to 6 months. Hence there is remodelling and mature bone forms once again. Within physiological limits, the stress concentration results in increased bone density of perifixtural bone $(24,27)$. On radiographs this in demarcated by radiopaque horizontal laminations radiating from the edges of the fixture threads (29). However repetitive undue forces which will cause circumfixtural osseous remodelling will result in nonmineralised connective tissue. Radiographically there will be increased radiolucency of particularly the marginal and also perifixtural bone. Studies have been consistent in showing locations of stress concentrations. For endosteal implants, the stress concentration is greatest in crestal bone when subjected to lateral or transverse forces and in the apical area under normal or axial loads. If physiological limits are exceeded, vertical bone loss results with deepening of the gingival sulcus. It is well established that bone is ideally suited to withstand compressive loading and ligaments or tendons are suited to transfer tensile loads. In implants, the periodontal ligament is absent in this interface.

\section{CONCLUSION}

The long term healthy state of the anchoring bone and covering mucosa is preserved 1) by control of the masticatory load distribution by a perfectly fitting prosthetic construction, 2) by maintaining barrier towards oral cavity at the piercing abutment without persisting, deep inflammatory processes (2). In this respect the maintenance of the implant abutments with its optimal interface by the patient and professional provider team is vital for the longevity of the implant-supported prosthesis and overall success of the dental rehabilitation of the patient. Peri-implant infection should be controlled if it cannot be avoided absolutely during the operative and postoperative phase and subsequently. Failure of implants may also occur as a result of mechanical failure in the components of the implant (15). Hence reputable, well researched and reliable implant systems should be the option of choice in implant work.

Predictable success of endosseous dental implants is possible with a better understanding of the biology of the tissues surrounding the implant i.e. the I-T interface. This oral tissue-dental implant interface is a dynamic zone with remodelling activities of the osseous tissue and hence is arguably the ultimate predictor of implant longevity.

\section{ACKNOWLEDGEMENT}

The author would like to thank Mr. Razali Arshad for his patience in the drawing of the illustrations of this paper.

\section{REFERENCES:}

1. Albrektsson T, Zarb G, Worthington P, Eriksson A. The long term efficiency of currently used dental implants: A review and proposed criteria of success. Int. J. Oral Maxillofac. Implants 1986; 1: 11-25.

2. Becker A, Becker BE, Newman MG, Nyman D Clinical and microbiological findings that may contibute to dental implant failure. Int. J. Oral Maxillofac. Implants 1990; 5: 31-38.

3. Albrektsson T, Branemark PI, Hansson HA, Ivarsson B, Jonsson U. Ultrastructural analysis of the interface zone of titanium and gold implants. Adv. Biomater. 1982; 4: $167-177$.

4. Albrektsson T, Sennerby L, Kalebo P, Thomsen P. The interface zone of inorganic implants in vivo. Titanium implants in bone. Ann. Biomed. Eng. 1983; 11: $1-27$. 
5. Schroeder A, Zypen E, Stich H, Sutter F. The reactions of bone, connective tissue, and epithelium to endosteal implants with titanium-sprayed surfaces. Maxillofac Surg. 1981; 9: 15-25.

6. Listgarten MA, Lai CH. Ultrastructure of the intact interface between an endosseous epoxy resin dental implant and the host tissues J. Biol. Buccale 1975; 3: 13-28.

7. Buser D, Warrer K, Karring T, Stich H. Titanium implants with a true periodontal ligament: An alternative to osseointegrated implants. Int J Oral Maxillofac Implants. 1990; 5: 113-116.

8. Albrektsson T, Branemark Pi, Hansson HA, Lundstrom J. Osseointegrated titanium implants. Requirements for ensuring a long lasting, direct bone anchorage in man. Acta Orthop. Scand. 1981; 52(2): 155-170.

9. Adell R. Tissue integrated prosthesis in clinical dentistry. Int. Dent. J. 1985; 35(4): 259-265

10. Branemark PI, Zarb GA, Abrektsson T. Tissue integrated prostheses: osseointegration in clinical dentistry. Chicago: Quintessence 1985. Chapter 6, pg 129-143.

11. Eriksson RA, Adell R, Temperatures during drilling for the placement of implants using the osseointegration technique. J. Oral Maxillofac. Surg. 1986; 44: 4-7.

12. Jacobsson M. On bone behaviour after irradiation. Thesis Departments of Anatomy and ENT University of Goteborg, Sweden 1985.

13. Jacobsson M, Tjellstrom A, Albrektsson T; Thomsen P, Turesson I. Integration of titanium implants in irradiated bone. Histologic and clinical study. Ann. Orto Rhino Laryngol 1988; 97: 337-340.

14. Linder L, Albrektsson T, Branemark Pi, Hansson HA, Ivarsson B, Jonsson U, Lundstrom I. Electron microscopic analysis of the bone-titanium interface. Acta Ortho[p. Scand. 1983; 54(1): 45-52

15. Branemark PI. Osseointegration and its experimental background J. Prosthet. Dent. 1983; 50: 399-410.

16. Steflik DE, Parr GR, Sisk AL., Lake FT, Hanes PJ, Berkery DJ, Brewer P. Osteoblast activity at the dental implant-bone interface: Transmission election microscopic and high voltage electron microscopic observations. J. Periodontal. 1994; 65(5): 404-13.

17. Albrektsson T, Hansson HA, Ivarsson B., Interface analysis of titanium and zirconium bone implants.
Biomaterials 1985; 6 (2) 07-101.

18. Cochrane DL, Simpson J, Weber HP, Buser D. Attachment and growth of periodontal cells on smooth and rough titanium. J. Oral Maxillofac Implants 1994; Vol 9; 3: $289-297$.

19. Apse P, Ellen RP, Overall CM, Zarb GA. Microbiota and crevicular fluid collagenase activity in the osseointegrated dental implant sulcus: A comparison of sites in edentulous and partially edentulous patients. Periodontal Res. 1989; 24(2): 96-105.

20. Gargiulo AW, Wentz FM,Orban B. Dimensions and relations of the dentogingival junction in humans. J. Periodontal 1961; 32: 261-266.

21. Gould TRL, Westbury L, Brunette. DM. Ultrastructural study of the attachment of human gingiva to titanium in vivo. Prosthet. Dent. 1984; 52: 418 -420.

22. James RA, Schultz RL. Hemidesmosomes and the adhesion of junctional epithelial cells to metal implants - a preliminary report. J. Oral Implantol. 1973; 4: 294302.

23. Shalak R: Biochemical considerations in osseointegrated prosthesis. J. Prosthet. Dent 1983; 49: 843-848.

24. Branemark PI. Et al. Osseointegrated implants in the treatment of the edentulous jaw. Experience from a 10 year period. Scand. J. Plastic Reconstr. Surg. 16 (Suppl) 1977.

25. van Zyl PP, Grundling NL, Jooste CH, Terblanche E. Three dimensional finite element model of a human mandible incorporating six osseointegrated implants for stress analysis of the mandibular cantilever prostheses. Int J Oral \& Maxillofacial Implants. 1995; Vol 10 (1) : $51-57$.

26. Kinni ME, Hokama SN, CaPuto AA. Force transfer by osseointegration implant devices. Int. J. Oral Maxillofac Implants 1987; 1: 11-14.

27. Adell R, Lekholm U, Branemark PI, Lindhe J, Rockler S, Eriksson B, Lindvall AM, Yoneyama T, Sbordone L. Marginal tissue reactions at osseointegrated titanium fixtures. Swed Dent. J. (Suppl) 1985; 28: 175-181.

28. Lanyon LE. Functional strain as a deterrent for bone remodelling. Calcif. Tiss Int. 1984; 36: 556-561.

29. Breine U, Branemark PI Reconstruction of alveolar jaw bone. Scand. J. Plastic Reconst. Surg. 1980; 14: 23. 